\title{
A DECISÃO DE EMIGRAR Um estudo a partir da perspetiva da pluralidade disposicional
}

\author{
João Teixeira Lopes \\ Faculdade de Letras da Universidade do Porto, Porto, Portugal \\ José Pedro Silva e Rafaela Ganga \\ Instituto de Sociologia da Universidade do Porto, Porto, Portugal
}

Rui Machado Gomes

Faculdade de Economia da Universidade de Coimbra, Centro de Estudos Sociais da Universidade de Coimbra, Coimbra, Portugal

Dulce Magalhães

Faculdade de Letras da Universidade do Porto, Porto, Portugal

Henrique Vaz

Faculdade de Psicologia e de Ciências da Educação da Universidade do Porto, Porto, Portugal

Luísa Cerdeira

Instituto de Educação da Universidade de Lisboa, Lisboa, Portugal

Sílvia Silva e Paulo Peixoto

Faculdade de Economia da Universidade de Coimbra, Centro de Estudos Sociais da Universidade de Coimbra, Coimbra, Portugal

Maria de Lourdes Machado

Agência de Avaliação e Acreditação do Ensino Superior, Lisboa; Centro de Investigação de Políticas do Ensino Superior, Matosinhos, Portugal

\section{Rui Brites}

Instituto Superior de Economia e Gestão da Universidade de Lisboa, Centro de Investigação e Estudos de Sociologia, Lisboa, Portugal

\section{Tomás Patrocínio e Belmiro Gil Cabrito}

Instituto de Educação da Universidade de Lisboa, Lisboa, Portugal

Resumo Este artigo analisa a emigração portuguesa qualificada, focando-se sobre a produção da decisão de emigrar. É seu objetivo compreender as disposições que conduzem a essa decisão, bem como os processos sociais que explicam a sua génese, sedimentação e ativação. Para isso, e recorrendo à proposta teórica e metodológica de Bernard Lahire, procede-se à análise transversal de 53 retratos sociológicos de portugueses qualificados que emigraram para outros países europeus, complementada pelos dados de um inquérito administrado previamente. Deste modo, daremos conta da forma como as disposições migratórias se constroem através dos percursos biográficos, ressaltando as potencialidades heurísticas da escala individual de observação.

Palavras-chave retratos sociológicos, emigração qualificada, fuga de cérebros.

Abstract This paper analyses the Portuguese high-skilled emigration, focusing on the emigration decision-making process. This article aims to understand the dispositions leading to this decision, and the social processes that explain its origin, sedimentation and activation. To this end, and using the theoretical and methodological approach of Bernard Lahire, 53 sociological portraits of skilled Portuguese who emigrated to other European countries are cross-sectional analyzed. This analysis is supplemented by data from a survey previously administered. Thus, we will address how the migratory dispositions are built through the individual biographies, highlighting the heuristic potential of the individual observation scale.

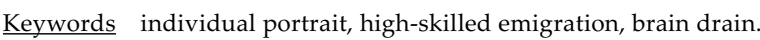


Résumé Cet article analyse l'émigration portugaise qualifiée, en se concentrant sur la production de la décision d'émigrer. Son objectif est de comprendre les règles qui conduisent à cette décision, et les processus sociaux qui expliquent sa genèse, sa sédimentation et son activation. A cette fin, et en utilisant l'approche théorique et méthodologique de Bernard Lahire, on procède à l'analyse transversale de 53 portraits sociologiques de portugais qualifiés qui sont émigrés vers d'autres pays européens, complétées par les données d'une enquête réalisée précédemment. Ainsi, nous allons rendre compte de la façon dont les dispositions migratoires sont construites à travers les biographies, mettant en évidence le potentiel heuristique de l'échelle d'observation individuelle.

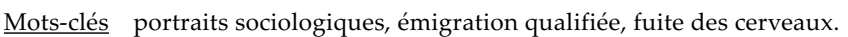

Resumen Este artículo analiza la emigración cualificada portuguesa, enfocándose sobre la producción de la decisión de emigrar. Su objetivo es comprender las disposiciones que conducen a esa decisión, así como los procesos sociales que explicam su génesis, sedimentación y activación. Para eso, y recurriendo a la propuesta teórica y metodológica de Bernard Lahire, se procede a un análisis transversal de 53 perfiles sociológicos de portugueses cualificados que emigraron para otros países europeos, sendo complementado por los datos de una encuesta hecha previamente. De este modo, nos permite verificar como las disposiciones migratorias se constituyen a través de el itinerario biográfico, resaltando todas las potencialidades heurísticas de la escala individual de observación.

Palabras-clave retratos sociológicos, emigración calificada, fuga de cerebros.

\section{A questão de pesquisa a partir de uma escala biográfica}

Este artigo apresenta e analisa percursos biográficos de indivíduos que decidiram emigrar e que possuíam cumulativamente as seguintes caraterísticas: (i) serem detentores de um diploma do ensino superior (ou desempenhando ou tendo desempenhado funções profissionais compatíveis com essa habilitação); (ii) estarem a trabalhar ou a residir noutro país europeu (ou tendo-o feito nos últimos seis anos). Os casos em apreço, selecionados em "bolas de neve" simultâneas, foram estudados no âmbito de um projeto científico, apoiado pela Fundação para a Ciência e a Tecnologia e envolvendo várias universidades (Coimbra, Lisboa, Porto), ${ }^{1}$ com o fim de conhecer a cadeia de motivos que estão na origem destes novos perfis de emigração, percebendo em que medida a decisão de uma mobilidade migratória, inicialmente determinada por razões inscritas nos percursos formativos e de trabalho, se transforma (ou não) numa mobilidade social incrustada num processo de socialização e com repercussões profundas nos sistemas de disposições individuais.

Sendo o êxodo de competências um fenómeno multifacetado (Baldwin, 1970; Beine, Docquier e Rapoport, 2008; Malheiros, 2011; Meyer, 2001; Mountford, 1997; Pires et al., 2015), a estrutura metodológica do projeto segue a natureza relacional

1 O projeto "Brain Drain and Academic Mobility from Portugal to Europe" - Bradramo (PTDC/IVC-PEC/5049/2012) foi financiado por fundos nacionais através da Fundação para a Ciência e a Tecnologia (FCT/MEC) e cofinanciado pelo Fundo Europeu de Desenvolvimento Regional (Feder) através do Compete - Programa Operacional Temático Fatores de Competitividade. 
do seu objeto de estudo, aplicando focus group (numa fase exploratória), um inquérito por questionário (administrado online a uma amostra intencional não aleatória composta por 1011 indivíduos, de modo a caracterizar os fatores de atração e repulsão presentes na decisão de emigrar, bem como os efeitos de de-skilling, re-skilling e up-skilling resultantes do processo de emigração) e retratos sociológicos, com base em entrevistas biográficas.

Portugal é identificado como um dos países europeus onde a fuga de cérebros tem sido mais acentuada ao longo da última década. Verifica-se a emigração de uma população cada vez mais qualificada, essencialmente para países como o Reino Unido e a Alemanha. O resultado dos Censos de 2011 revela que os portugueses qualificados a viver nos países da OCDE constituem $10 \%$ do total dos imigrantes portugueses nesses mesmos países (INE, 2015). Todavia, países como Reino Unido e a Alemanha avançam valores superiores, que rondam os $20 \%$ (Office for National Statistics, 2015), o que leva a considerar que os valores estimados a partir das fontes nacionais traduzirão uma imagem sub-representada da emigração qualificada. O número de emigrantes portugueses qualificados residentes em países da OCDE registou uma taxa de crescimento de 87,5\% entre 2000/2001 e 2010/2011 (OECD-UNDESA, 2013).

A emigração de indivíduos qualificados desde países periféricos para países centrais tem sido interpretada a partir de dois modelos contrastantes: (i) o modelo do êxodo, que argumenta que os mais qualificados são forçados ao exílio, de forma a encontrar emprego e renumeração compatível com a sua formação; (ii) o modelo da diáspora, que enfatiza os benefícios mútuos de intercâmbios interculturais abertos pela circulação das elites cosmopolitas académicas, científicas e culturais.

O projeto de investigação "Brain Drain and Academic Mobility from Portugal to Europe", ambicionando observar a emigração qualificada portuguesa dos últimos anos, assenta o trabalho de pesquisa em cinco propostas analíticas que ultrapassam a perspetiva dual dos modelos apresentados:

- Brain drain. Esta proposta analítica, próxima do modelo do êxodo, avança que, dado o capital humano não ser rentabilizado na mesma sociedade ou país onde foi gerado, se verifica uma perda do capital investido na formação dos indivíduos que emigram. Observa-se, portanto, uma perda potencial de externalidades, que conduz a efeitos negativos sobre o crescimento económico e a formação de capital humano no país de origem (Miyagiwa, 1991; Haque e Kim, 1995). Deste modo, o retorno do investimento na formação perde-se na emigração dos recursos humanos qualificados. Assim, a fuga de cérebros redunda num subsídio aos países ricos, pois o crescimento da maioria dos países desenvolvidos decorre da concentração de capital humano (Hamilton, 2003; Castles e Miller, 2003).

- Beneficial brain drain. Esta segunda proposta parte da premissa de que, se a emigração de pessoas qualificadas resulta em maior rendimento individual, sendo isso possibilitado através do seu investimento em educação, então mais pessoas estarão disponíveis para investir na sua educação e na dos seus filhos, o que acabará por aumentar a taxa de retorno da educação nos países 
em desenvolvimento (Mountford, 1997). Estes pressupostos não são consensuais. Alguns autores defendem que a taxa da fuga de cérebros exerce um efeito positivo sobre a taxa de variação do stock de capital humano, considerado como um brain gain (Beine, Docquier e Rapoport, 2008; Docquier e Marfouk, 2007). Por outro lado, os modelos de Heuer (2011) revelam um forte efeito negativo das taxas de emigração sobre as taxas de emprego nos países de origem, o que sugere a existência de brain drain.

- Circulação fertilizante das elites. Presume-se aqui que a mobilidade internacional de pessoas qualificadas é usualmente temporária e assume características de troca de conhecimentos, competências e projetos, perspetiva próxima do modelo da diáspora. Este processo de circulação de pessoas e ideias é desejável tanto para os países desenvolvidos como para os países em desenvolvimento. Olesen (2002), assumindo uma posição crítica do impacto negativo, a curto prazo, da fuga de cérebros, afirma que o benefício para os países de origem pode ocorrer a médio prazo. Os sujeitos altamente qualificados que deixam os seus países de origem por mais de dez anos transferem tendencialmente para o país de origem capital humano, financeiro e social aquando do seu retorno, ultrapassando os efeitos negativos do curto prazo. Uma outra característica desta proposta analítica é a premissa de que, neste tipo de emigração, os motivos económicos representam apenas uma parte da motivação para a migração. A mobilidade qualificada ocorre independentemente dos benefícios salariais obtidos (Mahroum, 2000), podendo mesmo ser acompanhada de efeitos económicos negativos (Forster, 2000).

- Brain circulation. Esta proposta assenta na ideia da criação de redes - nas áreas científica ou empresarial - que têm por fim transferir tecnologia e conhecimento dos países de acolhimento para os países de origem (Breinbauer, 2007). Argumenta-se, de forma próxima ao modelo da diáspora, que o aumento da circulação de conhecimento e de pessoas, no contexto da globalização, é inevitável, independentemente do nível de desenvolvimento dos países de origem. O movimento temporário de pessoas altamente qualificadas parece complementar, com crescente frequência, a migração de longo prazo, especialmente entre os países industrializados (Straubhaar, 2000).

- Brain drain latente. Na última década, a mobilidade formativa - referente a formação académica graduada e/ou pós-graduada - acentuou-se. Assim, nesta proposta analítica avança-se que as saídas para estudar no exterior, com ou sem bolsa, originalmente planeadas como temporárias, podem tornar-se permanentes devido à inserção no mercado de trabalho dos países de destino, tendencialmente mais desenvolvidos, ou menos afetados pelo desemprego jovem (Pizarro, 2005). No entanto, não se ignora que um período de estudos no estrangeiro, seguido de uma experiência de trabalho no país de destino, pode tornar-se benéfico a médio prazo para o país de origem, em caso de retorno (Johnson e Regets, 1998).

No presente texto, analisaremos os resultados do nível biográfico de observação, tendo por base quer o inquérito aplicado (embora, neste caso, nos estejamos a 
restringir aos indivíduos que, para além de inquiridos, foram entrevistados para a elaboração dos retratos sociológicos), quer os retratos propriamente ditos. No primeiro caso, procuraremos sistematizar alguns dados sociográficos, com particular enfoque nas inserções socioprofissionais e trajetórias de classe. No segundo, daremos conta de como a decisão de emigrar se pode melhor compreender estudando ciclos e contextos de socialização.

\section{Retratos sociológicos e pluralidade disposicional}

Os retratos sociológicos partem da hipótese da pluralidade disposicional (Lopes, 2014). Tanto a coerência (que é possível existir em percursos lineares onde os mesmos princípios de socialização são constantemente ativados pelas situações, numa espécie de sobreaprendizagem) como a heterogeneidade (fruto da disparidade de orientações das multissocializações e da multiplicação de contextos, quadros de interação e papéis sociais) são "casos do possível", com graus, nuances e interseções finas e variadas, combinando-se em cada indivíduo através da constituição de singularidades ou "coeficientes de singularidade", eles mesmos resultado do cruzamento (único e irrepetível, embora enquadrável em tendências e, por vezes, em regularidades) de dimensões estruturais, institucionais, interacionais e biográficas (Costa, Lopes e Caetano, 2014).

Uma disposição (forma coerente, durável e sistemática de pensar, agir e sentir) tem uma determinada origem e trajetória, na qual ganha ou perde força, consoante é ou não ativada e mobilizada pelos contextos. Não podemos simplesmente "supô-la" como entidade omnipresente e omnipotente que ajusta automaticamente os indivíduos às situações (ou o presente ao passado). Muitas delas não são verdadeiramente disposições, uma vez que existem como meros recursos, capacidades ou competências. Para analisá-las, importa levar a sério a ideia de que a sociologia é, antes de mais, o estudo dos processos de socialização, necessariamente múltiplos em sociedades diferenciadas, complexas e compostas por esferas de atividade ou "mundos da vida" razoavelmente específicos e institucionalizados, assentes em conjuntos de agentes, valores e "domínios de práticas" (família, trabalho, lazer, sociabilidades, corpo...), amiúde decompostos em microcontextos, situações ou cenários de interação (Lahire, 1998 e 2002). Assim, existe uma multideterminação do grau de homogeneidade ou heterogeneidade do stock ou "património de disposições incorporadas pelos atores" no decurso das socializações. O indivíduo, ser plural, não é redutível a uma só fórmula disposicional (a "legitimidade cultural"; a "boa vontade cultural"; a "destituição", "o gosto pela necessidade"... enfim, o habitus coerente e unificado, "estrutura estruturada predisposta a funcionar como estrutura estruturante" - Bourdieu, 1997: 61), o que nos motiva a explorar prolongamentos críticos da teoria da prática de Pierre Bourdieu. 


\section{Perfis-tipo e retratos sociológicos}

A revisão da literatura sobre êxodo de competências e mobilidade científica e/ou académica (Baláz e Williams, 2004; Ackers, 2005; Casey et al., 2001; Peixoto, 2001) permitiu-nos a construção de perfis-tipo dos migrantes qualificados, de acordo com a definição de um tipo particular de relação com o fenómeno em estudo e com as hipóteses teóricas avançadas, cruzando quatro grandes princípios estruturantes: (i) características temporais da mobilidade: permanente ou temporária, de longo prazo ou transitória; (ii) posição social no sistema de emprego: segmento primário ou secundário do mercado de trabalho; (iii) perfil funcional no sistema de emprego: académicos e cientistas, outras profissões altamente qualificadas; (iv) tipo de mobilidade: direta (depois de ter entrado no sistema de emprego do país de origem), indireta ou latente (após um período de estudo no país de acolhimento).

Os quatro perfis-tipo construídos são os seguintes:

i. migração para um país europeu para o exercício de profissões no sistema científico ou no ensino superior;

ii. migração de longo prazo para um país europeu para trabalhar no segmento primário (equivalente às qualificações académicas) ou secundário (abaixo das qualificações académicas) do sistema de emprego;

iii. mobilidade estudantil europeia, que conduz à inserção nos segmentos primário ou secundário do sistema de emprego do país em que é feita a formação;

iv. mobilidade e circulação transitória ou pendular através de redes europeias de ciência, produção, serviços ou cultura.

Em função destas categorias selecionaram-se os indivíduos a serem retratados, numa relação de 12 a 14 indivíduos por cada perfil-tipo, num total de 53 retratos, número este que ultrapassou o previsto, uma vez que se considerou que a possibilidade de realizar mais retratos acrescentaria valor heurístico à investigação. Assim, foram contactados os respondentes do inquérito que se disponibilizaram a colaborar nas fases subsequentes do projeto e foram entrevistados todos aqueles que aceitaram ser retratados.

O guião de entrevista para a construção dos retratos é formulado como se de um guião de entrevista semidirectiva de cariz biográfico se tratasse, adequado porém aos objetivos da pesquisa em concreto. Logo, contém obrigatoriamente questionamentos sobre o posicionamento do ator em várias esferas da vida, domínios de atividade, papéis sociais, contextos e quadros de interação. O guião de entrevista assim aplicado tem três grandes objetivos: (i) apreender o património plural de disposições que formam o habitus destes jovens; (ii) relacionar sistemas de desigualdades de origem com desigualdades de percurso; e (iii) fomentar a reflexividade biográfica. Divide-se em três grandes blocos, sendo os dois primeiros aplicados no primeiro momento de entrevista e o terceiro bloco aplicado num segundo momento. Num primeiro bloco procura-se conhecer a trajetória no ensino superior; o segundo bloco debruça-se sobre outras dimensões da trajetória social e escolar; e, por 
fim, o terceiro bloco é o momento reservado à reflexão sobre fatores, causas e razões que contribuíram para a decisão de emigrar, sobre a situação geral da empregabilidade em Portugal e sobre as sugestões de (re)definição de políticas públicas de emigração

Realizaram-se entrevistas nos principais países recetores da emigração qualificada: Reino Unido, Alemanha, Bélgica, França, Suíça e Noruega, assim como, em alguns casos, em Portugal. As transcrições das entrevistas foram editadas até à transformação das mesmas num discurso fluente na primeira pessoa, dando conta da narrativa biográfica do sujeito. A construção dos 53 retratos, usando a metodologia prevista, obedeceu a um processo longo de redação e correção de várias versões, implicando em muitos casos a renovação da interação presencial com os entrevistados. A versão de cada um dos retratos foi aprovada pelos retratados, que autorizaram, ou não, a sua publicação, seja sob o uso do nome próprio ou de nome antropológico.

Antes de cada entrevista foi solicitado o preenchimento de um inquérito pré-retrato online, com o intuito de recolher informação prévia e sistematizada sobre o contexto familiar e a situação profissional antes e durante a emigração.

\section{Descrição sociográfica geral}

Comecemos a nossa análise a partir da descrição, em traços gerais, das principais características sociográficas dos 53 indivíduos entrevistados.

Um primeiro aspeto que deve ser referido consiste na predominância de indivíduos do sexo feminino, que totalizam $64,2 \%$ dos casos. Este é um dado que não surpreende, refletindo a tendência, desenhada ao longo dos últimos anos, para que as mulheres protagonizem trajetórias escolares mais longas do que os homens e, consequentemente, tenham uma maior presença no ensino superior (Costa, Lopes e Caetano, 2014).

Outro aspeto que imediatamente se destaca é a relativa juventude destes 53 indivíduos: quase dois terços (62,3\%) nasceram em 1980 ou depois desse ano. Metade deles são solteiros, $28,8 \%$ vivem em união de facto, e os restantes $21,2 \%$ são casados. Uma maioria muita clara $(80,2 \%)$ não tem filhos.

Relativamente à escolaridade, há que salientar as elevadas qualificações destes emigrantes. É verdade que, para integrar a nossa amostra, era necessário possuir um diploma de licenciatura ou, pelo menos, desempenhar ou ter desempenhado nos últimos seis anos uma função compatível com ele; no entanto, esse é o grau académico mais elevado obtido por apenas $20,8 \%$ dos entrevistados. O peso dos indivíduos detentores de mestrado é de $47,2 \%$, enquanto $18,9 \%$ completaram o doutoramento. Devemos referir também que, em 72,5\% dos casos, o grau académico mais elevado foi obtido em Portugal.

No que respeita aos países de residência, e se excluirmos três entrevistados que entretanto regressaram a Portugal e um outro que vive em Espanha, estes localizam-se na Europa central e do norte. São três as nações que se destacam: Alemanha, Bélgica e Reino Unido, vivendo em cada um destes países 20,8\% dos retratados. 


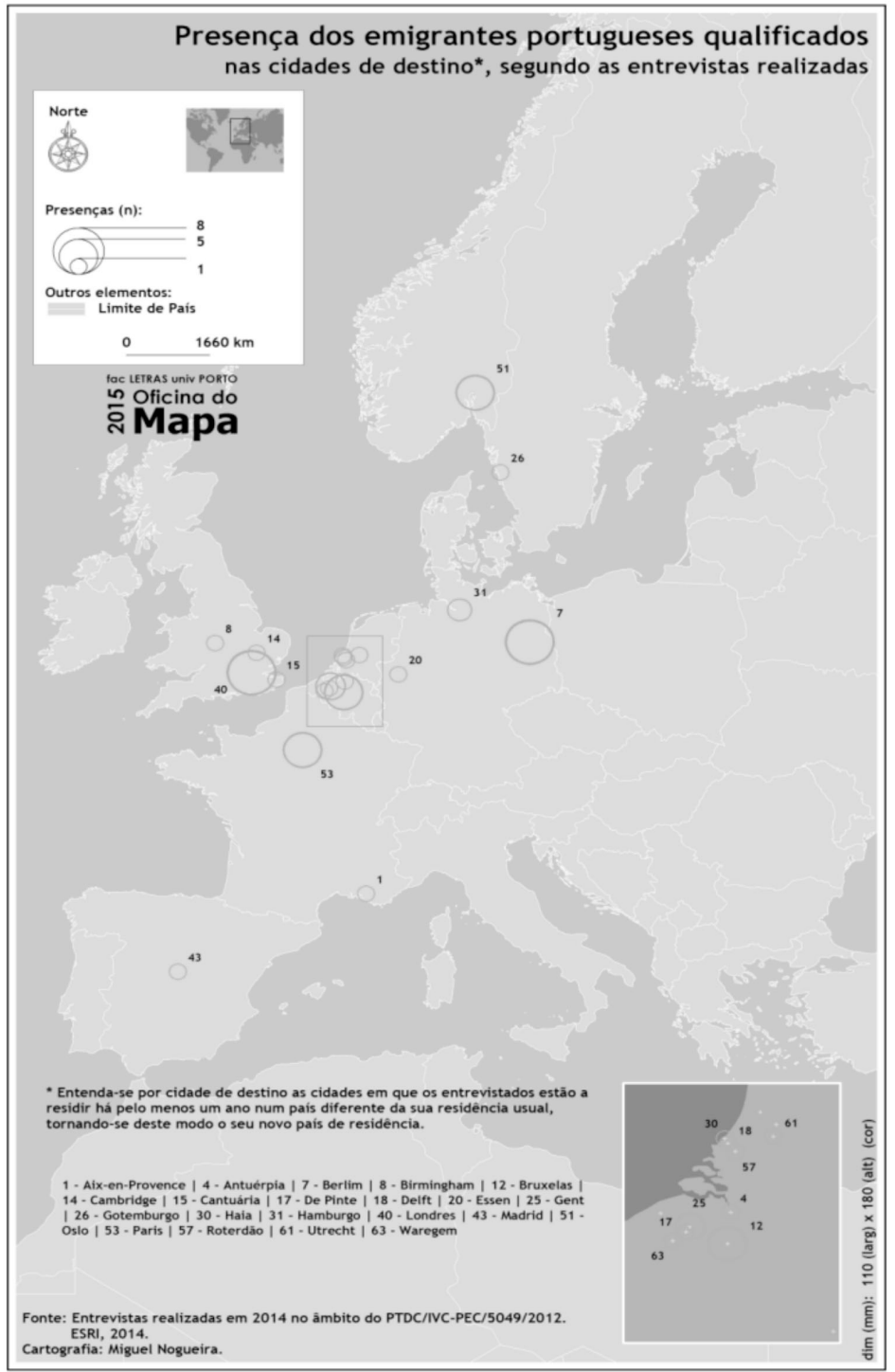

Figura 1 Presença dos emigrantes portugueses qualificados nas cidades de destino, ${ }^{*}$ segundo as entrevistas realizadas

Nota: * Entende-se por cidades de destino as cidades em que os entrevistados estão a residir há pelo menos um ano num país diferente da sua residência usual, tornando-se este consequentemente o seu novo país de redidência.

Legenda: 1 - Aix-en-Provence; 4 - Antuérpia; 7 - Berlim; 8 - Birmingham; 12 - Bruxelas; 14 - Cambridge; 15 - Cantuária; 17 - De Pinte; 18 - Delft; 20 - Essen; 25 - Gent;

26 - Gotemburgo; 30 - Haia; 31 - Hamburgo; 40 - Londres; 43 - Madrid; 51 - Oslo; 53 - Paris; 57 - Roterdão; 61 - Utrecht; 63 - Waregem.

Fonte: Entrevistas realizadas em 2014 no âmbito do PTDC/IVC-PEC/5049/2012. ESRI 2014.

Cartografia: Miguel Nogueira. 


\section{Efeitos da emigração sobre a situação profissional}

Apenas um pequeno número de entrevistados, totalizando quase $10 \%$ dos casos, estavam desempregados antes de emigrar. Quase um terço dos indivíduos $(32,6 \%)$ afirmaram ser estudantes em Portugal. Entre os que tinham uma ocupação profissional no país de origem - e que se distribuíam por diversos tipos de profissões, de uma forma geral qualificadas - destacam-se claramente aqueles que trabalhavam como investigadores, totalizando $18,6 \%$ de todos os entrevistados e tratando-se, na maior parte dos casos, de bolseiros de investigação. Estes dados sugerem-nos desde logo que, mais do que "empurrados" para fora de Portugal por uma necessidade absoluta, estes indivíduos "escolheram" viver e trabalhar noutros países. Após a emigração, e de um conjunto diversificado de profissões qualificadas - salvo algumas exceções - é mais uma vez a atividade de investigador que se destaca, desta vez com 31,7\% dos casos. Quase todos os entrevistados (83,7\%) consideram estar a desempenhar funções profissionais compatíveis com as suas qualificações académicas, e uma pequena minoria de $4,1 \%$ avalia o seu trabalho como sendo mais exigente do que as habilitações escolares que possui. A emigração permitiu, a muitos destes indivíduos, assegurar um vínculo profissional mais estável e, de uma maneira geral, uma remuneração mais elevada, como se demonstra na figura 2.

\section{Mobilidade social e mobilidade espacial}

Uma vez desenhado um retrato em traços gerais dos nossos 53 entrevistados, é o momento de percebermos, com maior detalhe analítico, os efeitos da emigração na trajetória social dos mesmos. Com esse intuito, captámos as posições do espaço social ocupadas por estes indivíduos em três momentos distintos da sua trajetória: o ponto de partida (isto é, a posição social da família de origem), a situação anterior à emigração, e a atual situação. Para isso, recorremos à matriz proposta por Dulce Magalhães (2005), que assenta nas primeiras versões da tipologia ACM, proposta desenvolvida e atualizada, ao longo de vários anos, por João Ferreira de Almeida, António Firmino da Costa e Fernando Luís Machado, em conjunto com outros autores. ${ }^{2}$ Fundamentais para a obtenção do lugar de classe nesta matriz (tal como, de resto, na tipologia $\mathrm{ACM}$ ) são a profissão e a situação na profissão dos indivíduos; como tal, ela já se encontra adaptada à mais recente versão da Classificação Portuguesa das Profissões, de 2011. A mais-valia desta matriz, comparativamente com as mais recentes versões da tipologia ACM, reside na leitura mais fina da realidade e mobilidade social que ela permite, a partir de um número de frações de classe. Deste modo, é possível captar de uma forma mais granular a complexidade do espaço

2 Como Magalhães (2005: 479) explica, a sua tipologia foi adaptada a partir da proposta publicada por Almeida, Costa e Machado (1988) e atualizada posteriormente pelos mesmos autores (Costa, Machado e Almeida, 1990), preferindo uma adaptação destas versões à utilização de outras mais recentes da mesma tipologia, por permitir uma melhor observação das clivagens entre diferentes frações de classe. 


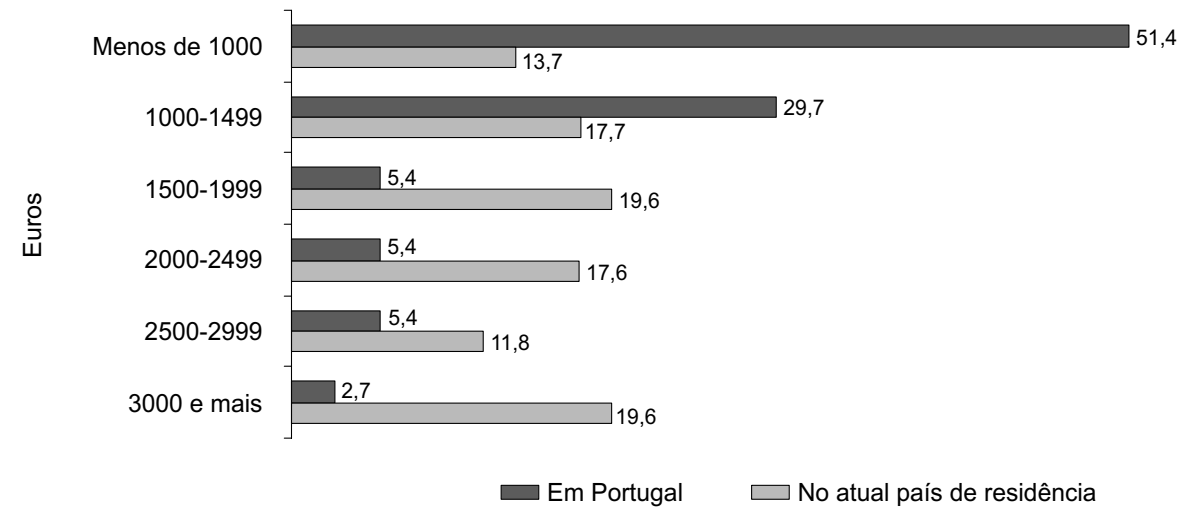

Figura 2 Remuneração mensal dos entrevistados em Portugal e no atual país de residência

social e a multiplicidade das posições que os indivíduos podem ocupar, e que, por sua vez, condicionam os seus contextos de socialização, as suas trajetórias e, consequentemente, o seu património de disposições.

Os dados revelam que a maior parte dos indivíduos que compõem a nossa amostra são oriundos de setores capitalizados do espaço social, tal como o quadro 1 ilustra.

Um aspeto que imediatamente ressalta da análise do quadro 1 é a completa ausência de entrevistados oriundos das posições mais penalizadoras da estrutura social, designadamente o operariado e o campesinato. Observa-se também uma clara sobrerrepresentação de indivíduos oriundos das diversas frações de classe da burguesia, com $37,7 \%$ dos casos, e o elevado peso das frações mais capitalizadas da pequena burguesia, ou seja, a pequena burguesia intelectual e científica $(30,2 \%)$ e a pequena burguesia técnica e de enquadramento intermédio (11,3\%). Considerando que a amostra é composta apenas de pessoas altamente qualificadas, os dados parecem confirmar que a posição social de origem dos indivíduos se encontra fortemente associada às trajetórias escolares por eles protagonizadas, com benefício daqueles que ocupam os lugares mais vantajosos do espaço social.

O quadro 2 dá conta das posições sociais ocupadas pelos entrevistados no momento em que tomam a decisão de emigrar. Devemos ressalvar que 14 indivíduos nunca tinham trabalhado em Portugal, por isso foi considerado nesse momento o seu lugar de classe de origem.

No momento da emigração, nenhum dos nossos entrevistados se encontrava posicionado nas frações de classe do operariado, distribuindo-se antes pela burguesia e pequena burguesia. O peso de indivíduos distribuídos pelas posições sociais associadas à primeira diminui face à classe de origem, mas mantém-se muito relevante $(24,5 \%)$, ao mesmo tempo que sobe a importância da pequena burguesia intelectual e científica, onde se encontravam localizados $49 \%$ dos sujeitos. Todavia, é necessário introduzir uma ressalva quanto ao elevado peso da burguesia: quatro dos sete casos classificados como pertencendo à burguesia profissional dizem respeito a pessoas que 
Quadro 1 Lugar de classe de origem dos entrevistados (lugares de classe compostos)

\begin{tabular}{llr}
\hline Classes & Frações de classe & $\begin{array}{c}\text { Número } \\
\text { de casos }\end{array}$ \\
\hline \multirow{2}{*}{ Burguesia } & Burguesia empresarial e proprietária (BEP) & 6 \\
& Burguesia dirigente (BD) & 10 \\
& Burguesia profissional (BP) & 1 \\
& Burguesia dirigente e profissional (BDP) & 3 \\
\hline Pequena burguesia & Pequena burguesia intelectual e científica (PBIC) & 16 \\
& Pequena burguesia técnica e de enquadramento intermédio (PBTEI) & 6 \\
& Pequena burguesia independente e proprietária (PBIP) & 5 \\
& Pequena burguesia proprietária e assalariada (PBPA) & 3 \\
& Pequena burguesia de execução (PBE) & 1 \\
& Pequena burguesia independente pluriativa (PBIP) & 1 \\
\hline Total & Pequena burguesia de execução pluriativa (PBEP) & 53 \\
\hline
\end{tabular}

Quadro 2 Lugar de classe no momento da emigração (lugares de classe compostos)

\begin{tabular}{llr}
\hline Classes & Frações de classe & $\begin{array}{c}\text { Número } \\
\text { de casos }\end{array}$ \\
\hline Burguesia & Burguesia empresarial e proprietária (BEP) & 2 \\
& Burguesia dirigente (BD) & 4 \\
& Burguesia profissional (BP) & 7 \\
\hline Pequena burguesia & Pequena burguesia intelectual e científica (PBIC) & 26 \\
& Pequena burguesia técnica e de enquadramento intermédio (PBTEI) & 4 \\
& Pequena burguesia independente e proprietária (PBIP) & 4 \\
& Pequena burguesia proprietária e assalariada (PBPA) & 1 \\
\hline Total & Pequena burguesia de execução (PBE) & 5 \\
\hline
\end{tabular}

estavam a exercer profissões intelectuais e científicas (professor, investigador, especialista de saúde) em condições de extrema precariedade, ou seja, em regime de "recibo verde" e, por vezes, a tempo parcial. Nestes casos, estamos perante indivíduos que serão detentores de um volume de capital cultural claramente superior ao seu capital económico - tal como acontece, de uma forma geral, no espaço social da pequena burguesia intelectual e científica. Apesar da sua classificação de classe, estes indivíduos não disporão, à partida, de um volume global e de uma composição de capital similares àquelas que são expectáveis para o espaço social da burguesia. De qualquer modo, e tal como já se antevia pela leitura do quadro referente às posições de classe de origem, confirma-se que, de uma forma geral, a partida destes indivíduos surge mais como uma escolha do que como o resultado de uma imposição - ideia que, de resto, já tínhamos avançado em momento anterior.

Após a emigração, mais uma vez, as franjas do campesinato e do operariado encontram-se ausentes. Para além de uma nova diminuição do número de burgueses, 
Quadro 3 Posição de classe após emigração

\begin{tabular}{llr}
\hline Classes & Frações de classe & $\begin{array}{c}\text { Número } \\
\text { de casos }\end{array}$ \\
\hline \multirow{2}{*}{ Burguesia } & Burguesia empresarial e proprietária (BEP) & 1 \\
& Burguesia dirigente (BD) & 1 \\
& Burguesia profissional (BP) & 6 \\
\hline Pequena burguesia & Pequena burguesia intelectual e científica (PBIC) & 41 \\
& Pequena burguesia técnica e de enquadramento intermédio (PBTEI) & 1 \\
& Pequena burguesia independente e proprietária (PBIP) & 1 \\
\hline Total & Pequena burguesia de execução (PBE) & 2 \\
\hline
\end{tabular}

que totalizam agora cerca de $15 \%$ da nossa amostra, destaca-se também o muito elevado peso de indivíduos classificados na posição de pequena burguesia intelectual e científica, perfazendo $77,3 \%$ dos casos. Tendo em conta que estamos perante uma amostra de emigrantes altamente qualificados, o elevado número de elementos desta fração de classe, aliado à importância dos indivíduos situados nas franjas da burguesia, indica desde logo uma elevada compatibilidade entre as qualificações académicas alcançadas e as profissões obtidas após a emigração.

\section{Coerências, dissonâncias, ruturas}

Interessa neste ponto analisar a divisão dos percursos em termos de coerência, heterogeneidade disposicional ou mesmo de rutura biográfica.

Esta opção analítica é, de alguma forma, artificial, mas necessária para que a classificação dos casos seja mutuamente exclusiva. São raros os percursos que, percorrendo os vários contextos de socialização e ciclos de vida, resultam num património individual de disposições inteiramente unificado e confirmado, incorporando a mesmidade e minimizando radicalmente a contradição e a dissonância. Pela multiplicidade de papéis sociais exercidos e pela plêiade de experiências vividas numa pluralidade de mundos da vida, todos os indivíduos apresentam algum coeficiente de diversidade disposicional.

Nesta análise consideramos que existe coerência disposicional quando se reúnem, mobilizam e intensificam mutuamente diversos quadros e experiências de socialização favoráveis ou desfavoráveis à decisão (efetivamente tomada) de emigrar. Nos casos de uma coerência disposicional favorável à emigração, esta surgirá como vocação, ou pelo menos fortemente embutida no percurso biográfico, nas suas múltiplas instâncias. No caso de uma coerência disposicional desfavorável à emigração, esta é vivenciada com sofrimento, desgosto e/ou rejeição.

$\mathrm{Na}$ análise dos casos de heterogeneidade, assistir-se-á a uma luta entre forças com graus diferentes de intensidade, em que as disposições mais enraizadas (porque mais precocemente interiorizadas e/ou porque mais ativa e sistematicamente 
mobilizadas) produzem oscilações, hesitações e um sentimento de ambiguidade relativamente à emigração. A rutura biográfica observa-se quando a heterogeneidade se radicaliza e o sujeito se vê compelido a fazer escolhas, muitas vezes infletindo o seu percurso, ou a decidir impasses com maior ou menor grau de ativação de mecanismos e recursos de reflexividade.

Na nossa amostra, 44 dos 53 sujeitos constituem casos de coerência disposicional favorável à emigração. Não foi observado qualquer caso de coerência disposicional desfavorável. Os casos de heterogeneidade disposicional são apenas sete. Esta concentração, não expectável face aos quadros teóricos de partida, demonstra a força com que certos processos sociais se reforçam mutuamente. Sublinha-se, neste âmbito, o treino de competências de autonomia, num mútuo reforço entre família e escola. Efetivamente, algumas propostas de educação escolar e não escolar facilitam dispositivos pedagógicos que potenciam o desenvolvimento da autonomia, sendo esta procurada por famílias que pretendam ativar nos seus filhos disposições de independência, o que facilitará o desapego face às condições sociais de origem, em alguns casos declinantes (ainda que relativamente privilegiadas).

A aprendizagem da autonomia aciona-se pelo ensaio, tentativa e erro, retificação e experimentação. Assim, observa-se que a capacidade de agência é intensamente treinada: os retratados demonstram como aprenderam a lidar reflexivamente com os seus percursos, confrontando-se com dificuldades várias, correspondentes a matrizes de escolhas e possibilidades. Um dos traços transversais marcantes deste perfil é o exercício de projetos de mobilidade (turística, juvenil, académica, profissional) geradora de competências e disposições emancipatórias face às origens sociais.

Com estes percursos foi possível compreender que a aquisição prematura de disposições cosmopolitas (em cursos de línguas, viagens, programas juvenis de cooperação...), facilita a decisão de emigrar para destinos urbanos, onde se podem encontram atmosferas sociais e culturais que valorizam os recursos humanos qualificados no setor "quaternário" da criação simbólica e estética e nos serviços que lidam com o processamento e a difusão de informação nas suas mais variadas formas.

Os percursos biográficos heterogéneos confrontam-se com lógicas competitivas de acumulação de capital social, em particular capital social de tipo inclusivo, através do qual se articulam papéis sociais diversificados (profissional, amigo, consumidor, espetador...) localizando e otimizando recursos multilocalizados (Putnam, 2002).

De igual modo, os percursos heterogéneos denotam a colisão entre diferentes esferas da vida na construção da disposição para a mobilidade, evidenciando assim a complexidade e pluralidade que cada indivíduo contém. Porém, eles revelam ainda que a emigração é, também, produtora de um certo desassossego. Em alguns dos casos de heterogeneidade observados, os sujeitos encontram-se numa situação profissional consideravelmente mais satisfatória do que aquela que conheciam em Portugal. Não obstante, observa-se a expressão de um certo sofrimento, provocado por um sentimento de perda - ou, pior ainda, de abandono - de laços fortes com pessoas que ficaram em Portugal que, mesmo que não seja suficientemente forte para que se lamente a decisão de emigrar, gera alguma ambivalência. 
Quadro 4 Contextos de ativação do processo migratório nos percursos de heterogeneidade

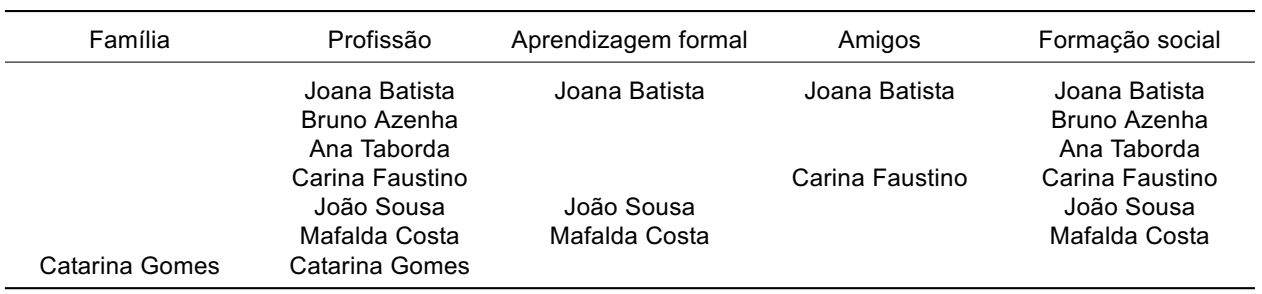

No quadro 4 observa-se que, apesar da pressão da "formação social" (o irromper e exacerbar da crise a partir de 2008) e da profissão serem centrais, as esferas social e afetiva também contribuem para a singularidade de cada percurso (Lahire, 2013).

Será interessante, ainda, considerarmos detalhadamente os raros casos de rutura biográfica (quadro 5).

Daniel Barradas é filho de uma família capitalizada que promove a aquisição de capital cultural institucionalizado e o exercício de práticas cultuais, quer recetivas quer ativas. A prossecução de estudos musicais, ainda que contra vontade, e depois de design gráfico, em Lisboa, não se afigura como estranha face ao contexto de partida. Quando tinha tudo para a internacionalização pela porta grande, em Nova Iorque, Daniel optou por aceitar o convite do namorado, que acabara de conhecer, para se mudar para a Noruega. As disposições cosmopolitas de Daniel saíram reforçadas pela inserção no mercado de trabalho norueguês, em vários empregos ligados ao design, pela inserção em redes gay e as inúmeras situações de abertura à diversidade. Face a uma situação de subemprego, Daniel regressou a Portugal, acompanhado pelo namorado. A crise de 2008 empurra-o novamente para a Noruega, onde inicia uma nova relação, acabando por casar. Hoje, ainda que não se sinta profissionalmente seguro, não descortina qualquer possibilidade ou desejo de regresso, dada a proteção social que a Noruega lhe oferece. Esta perceção inequívoca de um regresso improvável, associada à idade madura, torna-o nostálgico, o que mostra bem como o cosmopolitismo e o saudosismo podem coexistir.

A disposição para emigrar de Manuela Alcobia é ativada pela experiência de uma situação de rutura, produzindo ela própria reajustamentos subsequentes. Manuela trabalhou num hospital público, durante 13 anos, como técnica de saúde para diagnóstico genético. Porém, a estagnação da sua carreira na função pública, para a qual não são despicientes as políticas de austeridade adotadas em Portugal, articulada com instabilidade no trabalho do marido, com salários em atraso, obrigaram-na a optar pela emigração para evitar um ajustamento do estilo de vida face à nova realidade económica familiar. Assim, toda a família emigrou para Londres de forma planeada. Apesar das boas condições financeiras que experienciam no Reino Unido, Manuela mostra alguma angústia pelas relações que deixou em Portugal. Se o reconhecimento salarial é mais elevado do que em Portugal, o mesmo não acontece com reconhecimento profissional. Assim, ainda que 
Quadro 5 Fatores e processos de rutura biográfica

\begin{tabular}{ccc}
\hline $\begin{array}{c}\text { Momentos } \\
\text { (ciclo de vida) }\end{array}$ & $\begin{array}{c}\text { Contextos } \\
\text { (eclosão) }\end{array}$ & $\begin{array}{c}\text { Mudanças } \\
\text { (disposicionais) }\end{array}$ \\
\hline $\begin{array}{c}\text { Entrada na idade adulta } \\
\text { (Daniel Barradas) }\end{array}$ & $\begin{array}{c}\text { Relação afetiva } \\
\text { (Daniel Barradas) }\end{array}$ & $\begin{array}{c}\text { Sedimentação de disposições } \\
\text { cosmopolitas } \\
\text { (Daniel Barradas) }\end{array}$ \\
$\begin{array}{c}\text { Maternidade (3 filhos) } \\
\text { (Manuela Alcobia) }\end{array}$ & $\begin{array}{c}\text { Contexto profissional (seu e do } \\
\text { marido); crise económica } \\
\text { (Manuela Alcobia) }\end{array}$ & $\begin{array}{c}\text { Reconstrução da carreira } \\
\text { profissional } \\
\text { (Manuela Alcobia) }\end{array}$ \\
$\begin{array}{c}\text { Relação amorosa } \\
\text { (Eleonora Rodrigues) }\end{array}$ & $\begin{array}{c}\text { Inadaptação do companheiro a } \\
\text { (Eleonora Rodrigues) }\end{array}$ & $\begin{array}{c}\text { Regresso a Portugal, permanência } \\
\text { temporária do casal em casa de } \\
\text { familiares e recomeço de vida } \\
\text { autónoma em Espinho } \\
\text { (Eleonora Rodrigues) }\end{array}$ \\
\hline
\end{tabular}

temporariamente, Manuela regrediu profissionalmente e admite ter agora menos espaço para ser criativa no trabalho. Porém, diz-se confortável com a opção de emigrar, uma vez que agora considera que alcançou as condições para abrir múltiplas oportunidades de futuro para os três filhos. De igual modo, gosta do papel que a confiança tem nas relações laborais.

Por fim, Eleonora Rodrigues, com 31 anos, é natural de Lisboa mas vive em Espinho. Os pais (o pai era bacharel da escola do comércio e a mãe concluiu o ensino secundário), ainda que portugueses, nasceram e cresceram em Angola, chegando a Portugal após o 25 de Abril. Quando Eleonora tinha apenas três meses fizeram ainda uma passagem pelo Brasil, que durou três anos. Durante a adolescência de Eleonora, a empresa de importação/exportação que entretanto a família fundara faliu. Este acontecimento levou a que ela, com 16 anos, fosse viver com a irmã mais velha para Coimbra, adquirindo desde cedo uma certa autonomia. Durante a licenciatura em Comunicação Organizacional na Escola Superior de Educação de Coimbra fez Erasmus em Istambul, experiência rica em aprendizagens e sociabilidades e determinante para intensificar a vontade de conhecer o mundo. Licenciada e com experiência acumulada em múltiplos estágios não remunerados e trabalhos precários, inicia a desejada experiência profissional internacional através do programa Inov Contacto: um estágio de nove meses no Brasil, na área de assessoria e gestão de eventos. Regressa a Portugal e trabalha como assistente de marketing e de direção durante nove meses e passa novamente por múltiplos trabalhos precários. Durante este período conhece o atual companheiro, que partilha a sua condição profissional precária, o que os leva a decidir emigrar para Londres, em janeiro de 2013, apesar de alguma resistência dele. Londres é o destino de eleição pela língua e pelos laços sociais que já tinham na cidade. Eleonora consegue trabalho como advertising sales executive, orientada para o mercado brasileiro, mas descobriu que o seu chefe - um português - pagava salários inferiores aos trabalhadores oriundos de Portugal, Espanha e América Latina. Para além disso, o companheiro não se adaptou a Londres, gerando um mal-estar emocional que os fez regressar ao fim de 
três meses. Vivendo temporariamente em casa dos pais dele, Eleonora encontrou um estágio profissional de um ano, sem qualquer possibilidade de continuidade, voltado para o mercado brasileiro. Manifesta descontentamento com o elitismo do ensino superior, a precariedade do mercado de trabalho e as políticas públicas de emprego (Machado et al., 2003). Voltar a emigrar é uma possibilidade.

\section{Notas conclusivas}

Analisámos os percursos - sociais e biográficos - de um conjunto de 53 portugueses qualificados que decidiram emigrar para outro país europeu, procurando perceber, precisamente, que fatores contribuíram para essa tomada de decisão. Focámo-nos para isso nas posições por eles ocupadas na estrutura social e nos processos individuais de construção da disposição para emigrar. Os dois ângulos de análise podem parecer contraditórios, mas são na verdade complementares: as disposições dos sujeitos são construídas na interseção da sua individualidade com a ação de processos sociais mais vastos, e a forma como estes se traduzem em cada um não é indissociável da posição social ocupada.

Do ponto de vista da composição social da nossa amostra, verificámos que, de uma forma geral, os sujeitos que a integram são oriundos de famílias capitalizadas, ocupavam posições sociais compatíveis com o espaço da burguesia e, principalmente, com as áreas mais capitalizadas da pequena burguesia, e mantêm-se nas regiões mais favoráveis do espaço social após a emigração, concentrando-se notoriamente na fração de classe da pequena burguesia intelectual e científica. Tendo em conta as elevadas qualificações destas pessoas, as suas origens sociais não são surpreendentes. O predomínio das profissões intelectuais após a emigração revela a relativa facilidade com que foram encontrados trabalhos compatíveis com a formação académica.

Apesar das zonas do espaço social favoráveis ocupadas por muitos destes indivíduos antes de emigrarem, observa-se uma significativa melhoria das condições materiais de vida após a emigração, assentes num aumento do salário e numa maior segurança do vínculo laboral. As questões económicas e profissionais assumem elevada importância para a decisão de emigrar, o que sugere que mesmo aqueles que detêm um volume considerável de capital global, e especialmente de capital escolar, não têm, à partida, um percurso profissional estável e bem remunerado garantido no atual contexto nacional.

A importância das dimensões profissional e económica é reforçada quando voltamos a nossa atenção para os percursos marcados por processos de construção da disposição para emigrar marcados por contradições: em todos os casos de rutura, a dimensão profissional contribuiu para criar e ativar a disposição para emigrar, sobrepondo-se a outras esferas - por vezes a das relações familiares e amorosas, outras vezes a das sociabilidades amicais - que impeliam o indivíduo a continuar no país. E em todos os casos, exceto num, a dimensão formação social (e, mais especificamente, os efeitos económicos e sociais da crise que se fazem ainda sentir de forma severa no nosso país) contribuiu também para reforçar a vontade de sair. 
Não obstante a importância das duas esferas acima mencionadas, é de referir que a maior parte dos casos são de coerência disposicional, revelando uma construção da disponibilidade para emigrar que se reforça através de múltiplos planos da vida. Os retratos sociológicos revelam-nos que a decisão de emigrar surge fundamentalmente associada a percursos ligados à aquisição precoce de disposições para a autonomia e ao contacto com outras culturas (designadamente, mas não apenas, através da frequência de programas de mobilidade estudantil como o Erasmus), reforçando-se por vezes também na esfera das relações amorosas (emigrar para acompanhar o companheiro, ou para se reunir com ele). Por outro lado, os percursos de rutura, embora em número reduzido, mostram-nos como a decisão de emigrar pode gerar reajustamentos biográficos geradores de sofrimento, mas também de um incremento de reflexividade.

\section{Referências bibliográficas}

AA.VV. (2011), "Memorando da Troika anotado", Público, s.d., disponível em: http://www.publico.pt/economia/memorando-da-troika-anotado (última consulta em abril de 2016).

Ackers, L. (2005), "Promoting scientific mobility and balanced growth in the European reserach area", Inovation - The European Journal of Social Science Research, 18 (3), pp. 301-317, DOI: 10.1080/13511610500186680

Almeida, J. F. de, Costa, A. F. da; Machado, F. L. (1988), “Famílias, estudantes e universidade: painéis de observação sociográfica", Sociologia, Problemas e Práticas, 4, pp. 11-44.

Baláz, V., e A. Williams (2004), "Been there, done that: international students migration and human capital transfers from the UK to Slovakia", Population, Place and Space, 10 (3), pp. 217-237, DOI: 10.1002/psp.316

Baldwin, G. (1970), "Brain drain or overflow", Foreign Affairs, 48 (2), pp. 358-372.

Beine, M., F. Docquier, e H. Rapoport (2008), "Brain drain and human capital formation in developing countries: winners and losers", The Economic Journal, 118 (528), pp. 631-652, DOI: 10.1111/j.1468-0297.2008.02135.x

Bourdieu, P. (1997), Razões Práticas. Sobre a Teoria da Acção, Oeiras, Celta Editora.

Breinbauer, A. (2007), "Brain drain - brain circulation or... what else happens or should happen to the brains: some aspects of qualified person mobility/migration", FIW Working Paper, 4, disponível em: http://ideas.repec.org/p/wsr/wpaper/y2007i004.html (última consulta em abril de 2016).

Casey, T., S. Mahroum, K. Ducatel, e B. Rémi (2001), The Mobility of Academic Researchers. Academic Careers \& Recruitment in ICT and Biotechnology. A Joint JRC/IPTS-ESTO Study, Bruxelas, European Commission.

Castles, S., e M. J. Miller (2003), The Age of Migration. International Population Movements in the Modern World, Basingstoke, Palgrave Macmillan.

Costa, A. F. da, Machado, F. L.; Almeida, J. F. de (1990), “Estudantes e amigos: trajectórias de classe e redes de sociabilidade", Análise Social, XXV (105-106), pp. 193-221. 
Costa, A. F. da, J. T. Lopes, e A. Caetano (2014), Percursos de Estudantes no Ensino Superior. Fatores e Processos de Sucesso e Insucesso, Lisboa, Editora Mundos Sociais.

Docquier, F., e A. Marfouk (2007), "Brain drain in developing countries", World Bank Economic, 21 (2), pp. 193-218.

Ferreira, V. S., e J. M. Pais (2010), Tempos e Transições de Vida. Portugal ao Espelho da Europa, Lisboa, Imprensa de Ciências Sociais.

Forster, N. (2000), "The myth of the international manager", International Journal of Human Resource Management, 11 (1), pp. 126-142.

Hamilton, K. (2003), Migration and Development. Blind Fact and Hand-to-Find Facts, Washington, DC, Migration Policy Institute.

Haque, N. U., e S.-J. Kim (1995), “Human capital flight: impact of migration on income and growth", IMF Staff Papers, 42 (3), pp. 577-607.

Heuer, N. (2011), “The effect of occupation-specific brain drain on human capital", Working Papers in Economic and Finance, 7, University of Tubingen.

INE - Instituto Nacional de Estatística (2015), “Estatísticas mensais de emprego e desemprego: maio de 2015", Destaque - Informação à Comunicação Social, 29/06/2015, disponível em:

https://www.ine.pt/xportal/xmain?xpid=INE\&xpgid=ine_destaques\&DESTAQUES dest_boui=224671301\&DESTAQUESmodo=2 (última consulta em abril de 2016).

Johnson, J. M., e M. Regets (1998), “International mobility of scientists and engineers to the US-brain drain or brain circulation?", NSF Issue Brief, pp. 98-316.

Lahire, B. (1998), L'Homme Pluriel. Les Ressorts de l'Action, Paris, Nathan.

Lahire, B. (2002), Portraits Sociologiques, Paris, Nathan.

Lahire, B. (2013), “O singular plural”, Cadernos do Sociófilo, IV caderno, pp. 16-26.

Lodigiani, E., L. Marchiori, e I. Shen (2013), “Revisiting the brain drain literature with insights from a general equilibrium world model", Fondation pour les Etudes et Recherches sur le Développement International, disponível em: http://www.ferdi.fr/ sites/www.ferdi.fr/files/lodigiani.pdf (última consulta em abril de 2016).

Lopes, J. T. (2014), “Retratos sociológicos: dispositivo metodológico para uma sociologia da pluralidade disposicional”, em L. L. Torres e J. A. Palhares, Metodologia de Investigação em Ciências Sociais da Educação, V. N. de Famalicão, Edições Húmus.

Machado, F. L., A. F. da Costa, R. Mauritti, S. Martins, J. L. Casanova, e J. F. de Almeida (2003), “Classes sociais e estudantes universitários: origens, oportunidades e orientações", Revista Crítica de Ciências Sociais, 66, pp. 45-80.

Magalhães, D. (2005), Dimensão Simbólica de Uma Prática Social. Consumo do Vinho em Quotidianos Portuenses, Porto, Faculdade de Letras da Universidade do Porto, tese de doutoramento.

Mahroum, S. (2000), "Highly skilled globetrotters: mapping the international migration of human capital", RED Management, 30 (1), pp. 23-31.

Malheiros, J. (2011), "Portugal 2010: o regresso do país de emigração? Notas e reflexões", JANUS.NET e-journal of International Relations, 2 (1), disponível em: http://observare.ual.pt/janus.net/images/stories/PDF/vol2_n1/pt/pt_vol2_n1_not3.p df (última consulta em abril de 2016).

Meyer, J.-B. (2001), “Network approach versus brain drain: lessons from the diaspora”, International Migration, 5, pp. 91-110, DOI: 10.1111/1468-2435.00173 
Miyagiwa, K. (1991), "Economies in education and the brain drain problem", International Economic Review, 32, pp. 743-759.

Mountford, A. (1997), "Can a brain drain be good for growth in the source economy?", Journal of Development Economics, 53 (2), pp. 287-303.

OECD-UNDESA (2013), “World migration in figures”, disponível em: http://www.oecd.org/els/mig/dioc.htm (última consulta em abril de 2016).

Office for National Statistics (2015), Statistical Bulletin. Migration Statistics Quarterly Report, May 2015, Office for National Statistics, UK, disponível em: http://www.ons.gov.uk/ons/rel/migration1/migration-statistics-quarterly-report/ma y-2015/stb-msqr-may-2015.html (última consulta em abril de 2016).

Olesen, H. (2002), "Migration, return and development: an institutional perspective", International Migration, 40 (4), pp. 125-151.

Peixoto, J. (2001), “Migration and policies in the European Union: highly skilled mobility, free movement of labour and recognition of diplomas", International Migration, 39 (1), pp. 33-61, DOI: 10.1111/1468-2435.00134

Pires, R. P., C. Pereira, J. Azevedo, I. E. Santo, e I. Vidigal (2015), Portuguese Emigration Factbook 2014, Lisboa, Observatório da Emigração, disponível em: http://www.observatorioemigracao.pt/np4/1269 (última consulta em abril de 2016).

Pizarro, J. M. (2005), Globalizados, pero Restringidos. Una Visión Latinoamericana del Mercado Global de Recursos Humanos Calificados, Santiago do Chile, Centro Latinoamericano y Caribeño de Demografia.

Putnam, RD (2002), Democracies in Flux. The Evolution of Social Capital in Contemporary Society, Nova Iorque, Oxford University Press.

Straubhaar, T. (2000), “International mobility of the highly skilled. Brain drain, brain gain or brain exchange?", Hamburgo, Discussion Paper, 88, Hamburgisches Welt-Wirtschafts-Archives.

João Teixeira Lopes. Professor catedrático do Departamento de Sociologia da FLUP e investigador do IS-UP, Via Panorâmica, s/n, 4150-564 Porto, Portugal. E-mail: jmteixeiralopes@gmail.com

José Pedro Silva. Investigador, Instituto de Sociologia da Universidade do Porto, Via Panorâmica, s/n, 4150-564 Porto, Portugal. E-mail: j.silva.pedro@gmail.com

Rafaela Ganga (corresponding author). Investigadora, Instituto de Sociologia da Universidade do Porto, Via Panorâmica, s/n, 4150-564 Porto, Portugal.

E-mail: rafaela.ganga@gmail.com

Rui Machado Gomes. Professor catedrático, Centro de Estudos Sociais da Universidade de Coimbra, Colégio de S. Jerónimo, Lg. de D. Dinis, apartado 3087, 3000-995 Coimbra, Portugal. E-mail: ramgomes@gmail.com 
Dulce Magalhães. Professora auxiliar do Departamento de Sociologia da FLUP e investigadora do IS-UP, Via Panorâmica, s/n, 4150-564 Porto, Portugal.

E-mail: dulcegracamagalhaes@gmail.com

Henrique Vaz. Professor auxiliar da Faculdade de Psicologia e de Ciências da Educação da Universidade do Porto e investigador do CIIE, R. Alfredo Allen, 535, 4200-135 Porto. E-mail: henrique@fpce.up.pt

Luísa Cerdeira. Professora auxiliar, Instituto de Educação da Universidade de Lisboa, Al. da Universidade, 1649-004 Lisboa, Portugal.

E-mail: luisa.cerdeira@ie.ulisboa.pt

Sílvia Silva. Investigadora, Centro de Estudos Sociais da Universidade de Coimbra, Colégio de S. Jerónimo, Lg. de D. Dinis, apartado 3087, 3000-995 Coimbra, Portugal.E-mail: ssilva@uc.pt

Paulo Peixoto. Professor auxiliar da Faculdade de Economia da Universidade de Coimbra e investigador do Centro de Estudos Sociais da Universidade de Coimbra, Colégio de S. Jerónimo, Lg. de D. Dinis, apartado 3087, 3000-995 Coimbra, Portugal.E-mail: pp@uc.pt

Maria de Lourdes Machado. Investigadora, Agência de Avaliação e Acreditação do Ensino Superior A3ES, Centro de Investigação de Políticas do Ensino Superior, R. 1.ํ de Dezembro, n. $\stackrel{\circ}{ } 399-4450$ Matosinhos, Portugal.

E-mail: lmachado@cipes.up.pt

Rui Brites. Professor do Instituto Superior de Economia e Gestão da Universidade de Lisboa e Investigador do Centro de Investigação e Estudos em Sociologia, Av. das Forças Armadas, 1649-026 Lisboa, Portugal. E-mail: rui.brites@outlook.com

Tomás Patrocínio. Professor auxiliar convidado, Instituto de Educação da Universidade de Lisboa, Al. da Universidade, 1649-004 Lisboa, Portugal.

E-mail: patrocinio.tomas@gmail.com

Belmiro Gil Cabrito. Professor associado aposentado, Instituto de Educação da Universidade de Lisboa, Al. da Universidade, 1649-004 Lisboa, Portugal. E-mail: b.cabrito@ie.ulisboa.pt

Receção: 26 de outubro de 2015 Aprovação: 21 de março de 2016 